\title{
Recovery from alopecia areata in a patient with autoimmune polyglandular syndrome type 3
}

\author{
Shinya Makino, Takeshi Uchihashi, Yasuo Kataoka and Masayoshi Fujiwara \\ Department of Internal Medicine, Osaka Gyomeikan Hospital, 5-4-8 Nishikujo, Konohana-ku, \\ Osaka 554-0012, Japan
}

Correspondence

should be addressed

to S Makino

Email

makinos@ares.eonet.ne.jp

\section{Summary}

Recovery from alopecia is rare in autoimmune polyglandular syndrome (APS). A 41-year-old male was admitted to our hospital with hyperglycemia. He developed alopecia areata (AA) 5 months before admission and developed thirst, polyuria, and anorexia in 2 weeks. His plasma glucose level upon admission was $912 \mathrm{mg} / \mathrm{dl}(50.63 \mathrm{mmol} / \mathrm{l})$ and $\mathrm{HbA} 1 \mathrm{c}$ was $13.7 \%$. Although urinary and plasma C-peptide levels showed that insulin secretion was not depleted, anti-insulinoma-associated antigen 2 antibody was present. In addition, measurement of thyroid autoantibodies revealed the presence of Hashimoto's thyroiditis. These findings suggested a diagnosis of APS type 3. The patient has showed signs of improvement with the continuation of insulin therapy. During the successful control of diabetes, he had total hair regrowth within 2-3 months. Human leukocyte antigen typing showed that DRB1*1501-DQB1*0602 and DQB1*0301 were present. Similar cases should be accumulated to clarify the association of APS type 3 with recovery from AA.

\section{Learning points:}

- Alopecia in diabetic patients is a suspicious manifestation of autoimmune type 1 diabetes.

- Patients with autoimmune type 1 diabetes specifically manifesting alopecia should be further examined for diagnosis of APS.

- Insulin-mediated metabolic improvement may be a factor, but not the sole factor, determining a favorable outcome of alopecia in patients with autoimmune type 1 diabetes.

\section{Background}

Alopecia areata (AA) is a tissue-specific, T cell-mediated autoimmune disease of the hair follicles (1) and is often associated with autoimmune polyglandular syndrome (APS) or autoimmune thyroid disease (AITD). The clinical features of AA are heterogenous with respect to age of onset, extent of involvement, and disease duration. The majority of patients present with limited patches of alopecia on the scalp that regrow spontaneously within 1 year, whereas an estimated $7-10 \%$ of patients may experience more extensive and chronic forms of the disease (2). Although the precise prognosis of AA in APS is uncertain, associated autoimmune disease is a possible factor that might predict poor outcomes of AA in APS (1).

Herein, we present a case of APS type 3 with a severe form of AA (76-99\% hair loss) that might not be predicted to show an improvement from hair loss (3). However, following the successful control of diabetes, the patient had total hair regrowth within 2-3 months. The patient has shown improvement for both diabetes and AA over the last 5 years. \footnotetext{
open 2 Access Unported License.
} 


\section{Case presentation}

A 41-year-old male was admitted to our hospital with hyperglycemia on 3rd February 2009. During a health check in 2007, his fasting plasma glucose was $115 \mathrm{mg} / \mathrm{dl}$ ( $6.38 \mathrm{mmol} / \mathrm{l})$ and $\mathrm{HbA} 1 \mathrm{c}$ was $6.3 \%$, indicating impaired glucose tolerance (IGT). In September 2008, he abruptly developed AA and complained of upper abdominal pain. He visited another hospital where he was diagnosed with a duodenal ulcer. At this time, his random plasma glucose level was $163 \mathrm{mg} / \mathrm{dl}(9.05 \mathrm{mmol} / \mathrm{l})$. On 10th December 2008, his random plasma glucose level was elevated to $303 \mathrm{mg} / \mathrm{dl}$ (16.70 mmol/l), but he did not receive any antidiabetic medication. In January 2009, his alopecia gradually worsened and he rapidly developed thirst, polyuria, and anorexia at 2 weeks before admission. He was referred to our hospital on 3rd February 2009. His plasma glucose level upon admission was $912 \mathrm{mg} / \mathrm{dl}(50.63 \mathrm{mmol} / \mathrm{l})$ and HbA1c was $14.1 \%$. Physical examination on admission showed that his skin and tongue were dry due to dehydration. He showed $\sim 80 \%$ of scalp hair loss (Fig. 1A and B), but his other body hair was normal.

\section{Investigation}

His height was $175 \mathrm{~cm}$ and weight was $84.0 \mathrm{~kg}$. His blood pressure was $126 / 80 \mathrm{mmHg}$. Laboratory findings revealed a red blood cell count of $509 \times 10^{4} / \mathrm{mm}^{3}$, hemoglobin of $16.1 \mathrm{~g} / \mathrm{dl}$, and hematocrit of $43.7 \%$. The white blood cell count was $13500 / \mathrm{mm}^{3}$ with $79 \%$ neutrophils, and his platelet count was $20.7 \times 10^{4} / \mathrm{mm}^{3}$. Serum electrolytes were as follows: $\mathrm{Na} 129 \mathrm{mEq} / \mathrm{l}(\mathrm{mmol} / \mathrm{l}) ; \mathrm{K} 4.7 \mathrm{mEq} / \mathrm{l}$ (mmol/l); $\mathrm{Cl} 92 \mathrm{mEq} / \mathrm{l}(\mathrm{mmol} / \mathrm{l}) ;$ and $\mathrm{Ca} 8.4 \mathrm{mg} / \mathrm{dl}$ $(2.10 \mathrm{mmol} / \mathrm{l})$. Serum blood urea nitrogen was $12.6 \mathrm{mg} / \mathrm{dl} \quad(4.75 \mathrm{mmol} / \mathrm{l}) ; \quad$ creatinine, $\quad 0.73 \mathrm{mg} / \mathrm{dl}$ $(64.5 \mu \mathrm{mol} / \mathrm{l})$; and uric acid, $6.8 \mathrm{mg} / \mathrm{dl}(404.5 \mu \mathrm{mol} / \mathrm{l})$. Total serum protein was $6.2 \mathrm{~g} / \mathrm{dl}$ with $63.6 \%$ albumin;
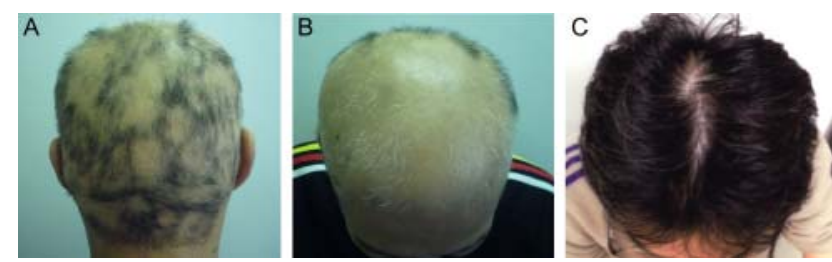

\section{Figure 1}

Alopecia areata (AA) in a patient with APS type 3. Approximately $80 \%$ of the scalp hair were lost at the time of admission ( $A$ and $B$ ). He had total hair regrowth within 2-3 months, and his AA has been under control for 5 years. $A A$ at 1.5 years after the initiation of insulin therapy (C).
AST, 85 IU/l; ALT, 135 IU/l; LDH, 251 IU/l; $\gamma$-GTP, 97 IU/l; and total cholesterol, $204 \mathrm{mg} / \mathrm{dl}(5.28 \mathrm{mmol} / \mathrm{l})$. Arterial blood gas analysis had a pH of 7.368; $\mathrm{PaO}_{2}, 81.4 \mathrm{mmHg}$; $\mathrm{PaCO}_{2}, 40.9 \mathrm{mmHg} ; \mathrm{HCO}_{3}, 23.0 \mathrm{mEq} / \mathrm{l}(\mathrm{mmol} / \mathrm{l})$; and base excess of $-2.1 \mathrm{mEq} / \mathrm{l}(\mathrm{mmol} / \mathrm{l})$.

As shown in Table 1, urinary and plasma C-peptide levels showed that insulin secretion was not depleted. Furthermore, islet cell antibodies, insulin autoantibodies, or anti-glutamic acid decarboxylase antibodies were not detected. However, anti-insulinoma-associated antigen 2 (IA-2) antibodies were present, suggesting autoimmune type 1 diabetes. In addition, an examination of thyroid autoantibodies revealed the presence of Hashimoto's thyroiditis. Plasma cortisol and adrenocorticotropin (ACTH) were normal, indicating no presence of Addison's disease. These findings suggested a diagnosis of APS type 3. HLA typing showed that DRB1*1501-DQB1*0602 and DQB1*0301 were present (Table 2).

Table 1 Autoimmune antibodies and basal hormonal levels in a patient with APS type 3 and AA.

\begin{tabular}{|c|c|c|}
\hline & $\begin{array}{l}\text { Conventional unit } \\
\text { (normal range) }\end{array}$ & SI unit \\
\hline Anti-GAD-Ab & $<0.4 \mathrm{U} / \mathrm{ml}(<1.5)$ & \\
\hline Anti-IA-2-Ab & $1.1 \mathrm{U} / \mathrm{ml}(<0.4)$ & \\
\hline ICA & $(-)$ & \\
\hline Insulin-Ab & $5.1 \%(<10)$ & \\
\hline Anti-nuclear Ab & $<\times 40(<40)$ & \\
\hline Anti-TPO-Ab & $26.0 \mathrm{U} / \mathrm{ml}(<0.3)$ & \\
\hline Anti-thyroglobulin-Ab & $197.0 \mathrm{U} / \mathrm{ml}(<0.3)$ & \\
\hline Mitochondrial (M2)-Ab & $<5(<7)$ & \\
\hline Anti-LKM-1-Ab & $<5(<17)$ & \\
\hline C-peptide (plasma) & $\begin{array}{l}1.26 \mathrm{ng} / \mathrm{ml} \\
(0.74-3.48)\end{array}$ & $0.427 \mathrm{nmol} / \mathrm{l}$ \\
\hline C-peptide (urine) & $\begin{array}{l}53.4 \mu \mathrm{g} / \mathrm{day} \\
(10.5-167.9)\end{array}$ & $17.7 \mathrm{nmol} / \mathrm{day}$ \\
\hline $\mathrm{TSH}$ & $\begin{array}{l}2.24 \mu \mathrm{lU} / \mathrm{ml} \\
\quad(0.38-3.64)\end{array}$ & $2.24 \mathrm{IU} / \mathrm{I}$ \\
\hline Free $T_{3}$ & $3.2 \mathrm{pg} / \mathrm{ml}(2.1-4.1)$ & $4.92 \mathrm{pmol} / \mathrm{l}$ \\
\hline Free $\mathrm{T}_{4}$ & $1.1 \mathrm{ng} / \mathrm{dl}(0.9-1.7)$ & $14.2 \mathrm{pmol} / \mathrm{l}$ \\
\hline ACTH & $29 \mathrm{pg} / \mathrm{ml}(7-56)$ & $6.39 \mathrm{pmol} / \mathrm{l}$ \\
\hline Cortisol & $10.2 \mu \mathrm{g} / \mathrm{dl}(4.5-21.1)$ & $281.4 \mathrm{nmol} / \mathrm{l}$ \\
\hline Testosterone & $\begin{array}{l}4.27 \mathrm{ng} / \mathrm{ml} \\
\quad(2.01-7.50)\end{array}$ & $14.8 \mathrm{nmol} / \mathrm{l}$ \\
\hline $\mathrm{LH}$ & $\begin{array}{c}3.02 \mathrm{mlU} / \mathrm{ml} \\
(0.79-5.72)\end{array}$ & $3.02 \mathrm{IU} / \mathrm{I}$ \\
\hline $\mathrm{FSH}$ & $\begin{array}{l}3.26 \mathrm{mlU} / \mathrm{ml} \\
(2.00-8.30)\end{array}$ & $3.26 \mathrm{IU} / \mathrm{I}$ \\
\hline Intact PTH & $\begin{array}{l}87.2 \mathrm{pg} / \mathrm{ml} \\
(10.0-65.0)\end{array}$ & $9.59 \mathrm{pmol} / \mathrm{l}$ \\
\hline
\end{tabular}

APS, autoimmune polyglandular syndrome; AA, alopecia areata; GAD, glutamic acid decarboxylase; IA-2, insulinoma-associated antigen 2; ICA, islet cell cytoplasmic antibodies; TPO, thyroperoxidase; LKM, liver kidney microsomal. 
Table 2 HLA DNA typing in a patient with APS type 3 and AA.

\begin{tabular}{lrr}
\hline A & $\frac{110101}{150101}$ & $\frac{260301}{5603}$ \\
B & $\frac{0102}{1202}$ & $\underline{030301}$ \\
C & $\frac{1501}{0102}$ & $\frac{0601}{0601}$ \\
DRB1 & $\underline{030101}$ & $\underline{0601}$ \\
DQA1 & $\underline{1010}$ & \\
\hline
\end{tabular}

HLA, human leukocyte antigen; APS, autoimmune polyglandular syndrome; AA, alopecia areata. Underline indicates HLA phenotypes.

\section{Treatment, outcome, and follow-up}

Intensive insulin therapy was initiated and plasma glucose levels were normalized in a couple of days. Since the initiation of treatment, the patient has improved following the continuation of insulin therapy. The HbA1c levels are controlled at 6.1-6.5\% over 6-8 units/day insulin. He has not developed major diabetic complications such as neuropathy, nephropathy, or retinopathy over the course of disease. Anti-IA-2 antibodies are continuously positive but plasma C-peptide levels are maintained within the normal range, suggesting slowly progressive type 1 diabetes. During successful diabetic control, he had total hair regrowth within 2-3 months. Over the last 5 years, the patient has been in a good condition for both diabetes and AA (Fig. 1C).

\section{Discussion}

APS is characterized by a combination of at least two endocrine organ failures mediated by autoimmune mechanisms. It is classified into four subtypes, namely APS types 1, 2, 3, and 4 (4) (5). Type 3 APS comprises AITD and type 1 diabetes without Addison's disease. Type 3 APS also includes non-endocrine organ-specific autoimmune disorders such as pernicious anemia and/or alopecia. The patient in this case study had type 1 diabetes, Hashimoto's thyroiditis, and AA, but lacked Addison's disease. Thus, the patient could be diagnosed as having type 3 APS.

Type 1 diabetes is classified as fulminant, acute-onset, or slowly progressive, depending on the way of onset and progression (6). This patient already had IGT for at least 1 year before he entered the apparent hyperglycemic state in December 2008. Although he developed hyperglycemic symptoms and was admitted with pre-diabetic ketosis $<3$ months after the onset of the hyperglycemic state, the presence of IGT for at least 1 year indicated that he should be diagnosed as slowly progressive, but not acute-onset, type 1 diabetes. As plasma C-peptide levels were maintained within the normal range for 5 years, this also supports the diagnosis of slowly progressive type 1 diabetes. In accordance with this, Horie et al. (7) reported that the frequency of HLA DRB ${ }^{*} 0803-\mathrm{DQB} 1{ }^{*} 0601$, a protective haplotype for abrupt-onset type 1 diabetes in Japanese population, was significantly lower in type 1 diabetes without AITD, but not in type 1 diabetes with AITD.

In this patient, total hair regrowth was observed within 2-3 months after the initiation of insulin therapy. Aw \& Cheah (8) showed that AA totalis, which developed simultaneously with diabetes mellitus, was improved after insulin therapy, indicating that the recovery from metabolic disturbance was involved in regrowth of the hair. Taniyama et al. (9) also reported a case of simultaneous development of type 1 diabetes and AA universalis. However, they found that alopecia did not regress after the metabolic state improved following insulin therapy. Taken together, insulin-mediated metabolic improvement may be one of the number of factors determining the favorable outcome of AA.

There are a number of reports showing that alopecia is a manifestation of APS types 2 and 3 (10) (11) (12) (13). Of these, two studies reported no recovery from alopecia (12) (13), and the others did not describe the outcome of alopecia. Thus, a precise prognosis of AA in APS is uncertain; however, the severity of AA at disease onset and associated autoimmune diseases are possible factors that might predict a poor outcome in AA (1) (3). Tosti et al. (3) found that the severity of AA at disease onset was the most important negative prognostic factor in adults, and that patients with $>50 \%$ of scalp hair loss tended to remain stable or worsen over time. In this regard, this is a very rare case that recovered from a severe form of AA ( 76-99\% hair loss) with multiple autoimmune diseases, namely APS type3.

His HLA typing showed that DRB1*1501-DQB1*0602, a protective haplotype for Japanese APS type 3 (14), and DQB1*0301, a susceptible allele for AA (1), were present. Interestingly, another case of APS type 3 with alopecia also had the HLA DRB1*1501-DQB1*0602 haplotype, similar to this patient (10). At present, it is uncertain whether APS type 3 with alopecia in these two patients is associated with this protective haplotype because most reports focusing on alopecia in APS types 2 and 3 lack genetic analyses (11) (12) (13). Therefore, it is important to accumulate similar cases to the one presented herein and such cases should include genetic analysis including HLA typing, to clarify the factors or mechanisms involved in pathogenesis and recovery from AA in APS. 


\section{Declaration of interest}

The authors declare that there is no conflict of interest that could be perceived as prejudicing the impartiality of the research reported.

\section{Funding}

This research did not receive any specific grant from any funding agency in the public, commercial or not-for-profit sector.

\section{Patient consent}

Written informed consent was obtained from the patient for publication of this case report.

\section{Author contribution statement}

$S$ Makino was the physician responsible for the patient and he reviewed and edited the manuscript. T Uchihashi, Y Kataoka, and M Fujiwara were the patient's physicians.

\section{Acknowledgements}

The authors wish to thank the medical technologists of Osaka Gyomeikan Hospital and Fukuyama Medical Laboratories, Inc. for their technical support.

\section{References}

1 Kos L \& Conlon J 2009 An update on alopecia areata. Current Opinion in Pediatrics 21 475-480. (doi:10.1097/MOP.0b013e32832db986)

2 Alexis AF, Dudda-Subramanya R \& Sinha AA 2004 Alopecia areata: autoimmune basis of hair loss. European Journal of Dermatology 14 364-370.

3 Tosti A, Bellavista S \& Iorizzo M 2006 Alopecia areata: a long term follow-up study of 191 patients. Journal of the American Academy of Dermatology 55 438-441. (doi:10.1016/j.jaad.2006.05.008)

4 Neufeld M, Maclaren NK \& Blizzard RM 1981 Two types of autoimmune Addison's disease associated with different polyglandular autoimmune (PGA) syndromes. Medicine 60 355-362. (doi:10.1097/00005792198109000-00003)
5 Betterle C, Dal Pra C, Mantero F \& Zanchetta R 2002 Autoimmune adrenal insufficiency and autoimmune polyendocrine syndromes: autoantibodies, autoantigens, and their applicability in diagnosis and disease prediction. Endocrine Reviews 23 327-364. (doi:10.1210/edrv.23. 3.0466)

6 Kawasaki E, Maruyama T, Imagawa A, Awata T, Ikegami H, Uchigata Y, Osawa H, Kawabata Y, Kobayashi T, Shimada A et al. 2014 Diagnostic criteria for acute-onset type 1 diabetes mellitus (2012): Report of the Committee of Japan Diabetes Society on the Research of Fulminant and Acute-onset Type 1 Diabetes Mellitus. Journal of Diabetes Investigation 5 115-118. (doi:10.1111/jdi.12119)

7 Horie I, Kawasaki E, Ando T, Kuwahara H, Abiru N, Usa T, Yamasaki H, Ejima E \& Kawakami A 2012 Clinical and genetic characteristics of autoimmune polyglandular syndrome type 3 variant in the Japanese population. Journal of Clinical Endocrinology and Metabolism 97 E1043-E1050. (doi:10.1210/jc.2011-3109)

8 Aw TC \& Cheah JS 1978 Diabetes mellitus presenting with alopecia areata totalis. Lancet 2 268. (doi:10.1016/S0140-6736(78)91783-X)

9 Taniyama M, Kushima K, Ban Y, Kaihara M, Nagakura H, Sekita S, Katagiri T \& Sueki H 1991 Simultaneous development of insulin dependent diabetes mellitus and alopecia areata universalis. American Journal of the Medical Sciences 301 269-271. (doi:10.1097/00000441199104000-00009)

10 Shimomura H, Nakase Y, Furuta H, Nishi M, Nakao T, Hanabusa T, Sasaki H, Okamoto K, Furukawa F \& Nanjo K 2003 A rare case of autoimmune polyglandular syndrome type 3. Diabetes Research and Clinical Practice 61 103-108. (doi:10.1016/S0168-8227(03)00115-3)

11 Sheehan MT \& Islam R 2009 Silent thyroiditis, isolated corticotropin deficiency, and alopecia universalis in a patient with ulcerative colitis and elevated levels of plasma factor VIII: an unusual case of autoimmune polyglandular syndrome type 3. Endocrine Practice $\mathbf{1 5}$ 138-142. (doi:10.4158/EP.15.2.138)

12 Quintyne KI, Barratt N, O’Donoghue L, Wallis F \& Gupta RK 2010 Alopecia universalis, hypothyroidism and pituitary hyperplasia: polyglandular autoimmune syndrome III in a patient in remission from treated Hodgkin lymphoma. BMJ Case Reports. (doi:10.1136/bcr.1110. 2009.2335)

13 Protic M, Gligorijevic V, Bojic D, Popovic B, Damjanovic S \& Jojic N 2013 Autoimmune polyglandular syndrome type 2 , alopecia universalis and Crohn's disease. Journal of Crohn's \& Colitis 7 318-321. (doi:10.1016/j.crohns.2012.05.009)

14 Hashimoto K, Maruyama H, Nishiyama M, Asaba K, Ikeda Y, Takao T, Iwasaki Y, Kumon Y, Suehiro T, Tanimoto N et al. 2005 Susceptibility alleles and haplotypes of human leukocyte antigen DRB1, DQA1, and DQB1 in autoimmune polyglandular syndrome type III in Japanese population. Hormone Research 64 253-260. (doi:10.1159/000089293)

Received in final form 26 November 2014 Accepted 29 January 2015 